\title{
Realistic evaluation as a volunteer tourism supply chain methodology
}

\begin{abstract}
Evaluations of how volunteer tourism projects fail or succeed tend to underestimate the importance of contextual factors affecting the mechanisms introduced to achieve a desired sustainability outcome. Realistic evaluation is a recently developed methodology to critically develop testable context-mechanism-outcome (CMO) propositions that explain what works, for whom, under which circumstances. Our study makes a theoretical contribution by uniquely integrating realistic evaluation with collaboration theory to study the volunteer tourism supply chain, in order to demonstrate how to develop an evaluative framework to map out the components of CMO configurations. Our study also makes a practical contribution by unpacking the black box of the mechanisms to deliver sustainable change through the supply chain of the volunteer tourism industry.
\end{abstract}

Keywords: volunteer tourism, evaluation, supply chain management, stakeholder collaboration 


\section{Introduction}

Volunteer tourism is a social intervention that attempts to achieve change through a transformational process based on the transfer of volunteers' skills, knowledge or resources at community level (Bussell \& Forbes, 2002; Taplin et al., 2014; Tomazos \& Butler, 2009). Volunteer tourism is understood to be sustainable when stakeholders perceive that their inputs and outputs are equitable; however recent studies have found that many volunteer tourism projects favour the needs of the volunteer or the mediating organisations, but not the needs of the supposed beneficiaries of the project (Burrai, Font, \& Cochrane, 2015; McGehee \& Andereck, 2009; Raymond \& Hall, 2008; Sin, Oakes, \& Mostafanezhad, 2015; Wearing \& McGehee, 2013). NEW REF

Recent media reports of dissatisfied volunteers and exploitation of vulnerable people, such as volunteering in orphanages, incite more research in volunteer tourism, but the root causes within the supply chain that lead to volunteers' dissatisfaction and intended beneficiaries such as host projects' exploitation are not fully understood. The voices of the supposed beneficiaries of the projects are usually not heard, because they are too far down the supply chain. To understand how these beneficiaries are affected by multiple decisions taken further up the supply chain, more research needs to be done to understand the motivations, values and policies that define volunteer tourism organisations' operational practices (e.g. Taplin et al., 2014; Lupoli et al., 2015; Lupoli \& Morse, 2014b). Hence it is important to unpack the black 
box of the mechanisms to deliver sustainable change through the supply chain of the volunteer tourism industry.

In this article, we show how a realist evaluation (RE) methodology can help capture evidence of the contextual conditions $(\mathrm{C})$ that condition the outcomes $(\mathrm{O})$ achieved from supply chain management mechanisms (M), usually explained as CMO configurations. Our study makes a theoretical contribution by uniquely integrating RE with collaboration theory, in order to demonstrate how to develop an evaluative framework to map out the components of CMO configurations in a supply chain. The realistic framework that we devise explores how volunteer tourism stakeholders' contextual conditions, such as their motivation and expectations, influence their collaborative relations with each other and consequently supply chain performance. We show several significant advantages to applying a theory-driven evaluation in volunteer tourism supply chain research. We contribute to the literature demonstrating how RE has the ability to deal with heterogeneity and allows for the systematic exploration of complex social circumstances and root causes (Astbury, 2013; Hunt \& Sridharan, 2010; Manzano-Santaella, 2011). Methodologically, we contribute by demonstrating how to systematically deconstruct complex social relations into specific CMO components to link causal explanations to particular outcomes. We show how this approach allows for more transferability and relevance for practitioners, and a fuller contribution to knowledge, by enabling the direct application of theory-driven evaluation (Marchal et al., 2016). 


\section{Realistic evaluation}

Evaluations i) analyse an intervention, including the input process, ii) measure the findings and outcomes, and iii) analyse the degree to which relationships occur (Coryn et al., 2010). Evaluation consists of the basic elements of input, output, a transformation process and feedback (Hall \& Hall, 2004). This transformation process is occasionally explained as a 'black box' (e.g. Astbury \& Leeuw, 2010) that describes the change which takes place based on a programme (Dillman, 2013; Jackson \& Kolla, 2012). The black box emphasises that a transformation process is context dependant, and evaluators are only able to determine causal explanations if the specific social intervention or mechanisms are fully understood.

The emphasis of realism is to find the root causes of a social phenomenon. Realism recognises that a social intervention can be considered as a social system, consisting of different social fabrics, such as processes, organisations, social structures and individuals. Pawson and Tilley (1987) apply concepts of realism to substantiate causal explanations based on such social systems in order to find the root causes of social change. They suggest that individuals and organisations interact in a stratified social reality, such as that of a supply chain, and argue that causal mechanisms are formed through the social processes of interactions and contexts (Marchal et al., 2016). In essence, RE determines 'what works for whom in what circumstances', developing a generative model of causation. An outcome is explained through the different contextual conditions and mechanisms by examining theory and observation in 
testing a social construction, and bridging theory and practice (Astbury, 2013; Hunt \& Sridharan, 2010; Manzano-Santaella, 2011; Manzano, 2016).

$\mathrm{RE}$ is a theory-driven robust approach that attempts to evaluate a certain occurrence or intervention of a social system causing a particular outcome (Pawson, 2013). RE tests and investigates how a particular outcome $(0)$ occurs, by exploring what particular circumstances (C) trigger certain actions $(\mathrm{M})$, as part of the $\mathrm{CMO}$ configuration of $\mathrm{C}+\mathrm{M} \rightarrow \mathrm{O}$. Following the collaboration paradigm, we argue that the black box consists of the collaborative relations between stakeholders, in our case, within the supply chain. Pawson and Tilley (1997) explain that RE determines a causal explanation of if-then (if the right contextual setting influences the social situation then change occurs). The causal relationship of the CMO configuration focuses on a certain context with an underlining mechanism that is based on a causal and conditional situation that results in the outcome. Thus, in simple terms, the CMO configuration changes accordingly over time $\left(T_{1}\right.$ and $\left.T_{2}\right)$ from $\mathrm{C}_{1} \mathrm{M}_{1} \mathrm{O}_{1}$ to $\mathrm{C}_{2} \mathrm{M}_{2} \mathrm{O}_{2}$. Figure 1 illustrates an operation intervention consisting of different contextual settings (Cs) and mechanisms (Ms) causing different outcomes (Os). In a similar manner, RE is applicable to determining the outcomes in volunteering supply chain collaborations.

*** insert Figure 1 here

$\mathrm{CMO}$ configurations are developed with desk research focused on policy documentation from public sources (Nanninga \& Glebbeek, 2011), followed by interviews with a variety of stakeholder groups, including the recipients of interventions (Byng et al., 2005; Wand et al. , 
2010). Byng et al. (2005) highlight the challenges of overcoming multiple Cs and Ms to accommodate the different circumstances and heterogeneity of the intervention. The feedback mechanisms involved in developing the CMO configurations are a critical part of the successful application of RE. They conclude that RE proves invaluable as a theoretical tool for determining the Contexts and Mechanisms, and that the process of determining the CMO configuration is critical (Byng et al., 2005). Furthermore, Wand et al. (2010) state that the process of developing the $\mathrm{CMO}$ framework supports their deeper understanding of the intervention, and of gaining knowledge about not just what, but also how. In order to understand the full nature of the intervention and its outcomes, it is crucial to incorporate unknown outcomes into the $\mathrm{CMO}$ configuration because the mechanism can unexpectedly change (Nanninga \& Glebbeek, 2011). Overall, these studies provide some useful insights into the development of $\mathrm{CMO}$ configurations, that we shall build on, in order to demonstrate how to build a map of Contexts, Mechanisms and Outcomes that allow the researcher to then identify multiple configurations. 


\section{Realistic evaluation and the stakeholder supply chain}

RE has been used to evaluate complex health, social welfare, education and law programmes (Greenhalgh et al., 2015; Marchal et al., 2016) and demonstrates the ability to gain deeper understandings of various expected and unexpected outcomes, as well as how and why they occur (Byng et al., 2005; Nanninga \& Glebbeek, 2011; Wand et al., 2010). The application of RE demonstrates its usefulness for practitioners and policy makers, in particular by going beyond the programme's outcomes to understand more about the antecedents for its mechanisms. To our knowledge, it has not been used to study inter-organisational behaviour such as collaboration in supply chains.

Academics have shown interest in evaluating the relative success of sustainability actions in supply chains, as seen in literature reviews (Ahi \& Searcy, 2015; Gold et al., 2010; Kache \& Seuring, 2014; Varsei et al., 2014), conceptual models (Beske \& Seuring, 2014; Schaltegger \& Burritt, 2014), and empirical studies (Dos Santos et al. 2014; Erol et al. 2011; Harms et al. 2013). Two main lines of enquiry have been used to evaluate sustainability in supply chains: i) efforts to measure performance indicators (Dos Santos et al., 2014; Erol et al., 2011; Varsei et al., 2014), and ii) to understand stakeholder collaborations (Beske \& Seuring, 2014; Gold et al., 2010; Kache \& Seuring, 2014).

Because evaluating supply chains does not just entail looking at one organisation, but at its complex relations to its consumers and suppliers when producing a product or service, this 
study follows the collaboration paradigm. Since a supply chain is not simply a linear chain or a causal relationship but is often complex and changeable (Tejada \& Liñán, 2009), it is important to examine how a supply chain may reflect the realities of how the stakeholders relate to one another. As a theory driven evaluation mechanism, RE allows us to build an evaluative framework using collaboration theory and supply chain management. Thus, RE's causal explanations are applicable to evaluate the relations between supply chain stakeholders and how these influence outcomes in certain contextual settings. Specifically, the mechanism in RE is significant in terms of examining the inside of the black box by applying collaboration theory to measure the collaborative relations. Thus, the construction of our evaluation framework is based on measuring stakeholder collaborations, using supply chain analysis, to understand how such relations cause certain sustainability performance outcomes.

The foundations to the CMO configurations to understand supply chains are outlined in Table 1. Based on the sustainable supply chain performance (Beske \& Seuring, 2014), the indicator dimensions (middle column) and performance categories (right column) are set against a basic CMO structure. From a collaboration theory point of view (Gajda, 2004), we argue that the different contextual settings of the stakeholders (C) consist of their strategic values. The mechanism (M) is based on the collaborative relations, including processes and their 
structural arrangements, i.e. governance. The outcomes $(0)$ are based on the supply chain sustainability performances of transformative social change over time.

*** insert Table 1 here

The integration of collaboration theory with RE entails a further step in the development of the evaluative framework. Based on sustainable supply chain management, the evaluative framework contextualises the individual indicator dimensions of strategic values, structure and processes, and defines the measurable indicator categories. According to Beske and Seuring (2014), collaboration is one of the indicator dimensions of the conceptual sustainability supply chain framework. In applying their framework to a CMO configuration and integrating collaboration theory, collaborative relations and sustainability performance in the supply chain become measurable. Collaborations can be understood based on their intensity, level of integration, degree of consensus, level of engagement and scope (Austin, 2000; Gajda, 2004). Thus, the integration of the different models (sustainability in supply chain management and indicator development) and theories (RE and collaboration theory) formulates the basis of the evaluative framework.

RE allows to systematically deconstruct the supply chain to analyse the performance of its main stakeholders at organisational, community or micro level (Dos Santos et al., 2014; Erol et al., 2011; Harms et al., 2013). Supply chain analysis examines the processes and activities involved in developing and delivering a product or service, and thus the inter-relationships 
between suppliers (Braziotis, et al., 2013). The systematic approach of RE provides validity and rigour to the evaluative framework. The framework evaluates the collaborative relations that exist within the different stakeholder groups and how these influence the outcomes. The $\mathrm{CMO}$ configuration can be measured first through process and subsequently through performance indicators, determined with a clear understanding of the contextual setting of how and why stakeholders collaborate. 


\section{A realistic evaluation supply chain analysis of volunteer tourism}

We shall now demonstrate in detail the process of identifying Cs, Ms and Os through the development of an analytical framework that applies RE to supply chain analysis. The development of a CMO framework is a critical step to understand the relations between suppliers within the supply chain and unpack the black box that requires further research (Beske \& Seuring, 2014; Gold et al., 2010; Kache \& Seuring, 2014). The volunteer tourism supply chain is typically made up of volunteers, who contract the services of a sending organisation that is based in the market source country who acts as a tour operator by developing, marketing and selling volunteering products. This sending organisation has contractual arrangements with a receiving organisation, usually an intermediary incoming tour operator in the destination that coordinates several local host projects with several sending organisations, to facilitate volunteer flows. The host project typically exists to address a socio-economic or environmental challenge in the destination country (e.g. education, health, conservation...). Although this is a common supply chain model, other supply chain models exist within volunteer tourism. For example, more simple supply chains without either a sending or receiving organisations, and where small local projects directly recruit volunteers, and communications is facilitated by the internet. However, within this supply chain model, the four stakeholders' motivations and expectations are more varied and complex which can lead to problematic and imbalanced relations (e.g. Jaeni \& Timonen, 2014; McGehee, 2014). 
Each stakeholder plays a specific part in contributing to the social intervention. Supply chain analysis, therefore, enables the evaluative framework to explore each of the stakeholders' contextual settings and assess how the social intervention is constructed. Significantly, supply chain analysis adds consistency and systematic structure to the process of investigating a complex social intervention, as it describes a logical flow within the supply chain (Astbury, 2013). Integrating RE, the evaluative framework assesses the stakeholders' collaborative relations (M), which consist of visible and observable processes, activities and communications. The contextual settings of each stakeholder consist of motivations, expectations and experiences (C) (Astbury, 2013; Dalkin et al., 2015; De Souza, 2013; Hunt \& Sridharan, 2010; Manzano-Santaella, 2011; Schmitt \& Beach, 2015), which influence certain outcomes and transformative change (O). Figure 2 provides an initial illustration of a typical $\mathrm{CMO}$ of the volunteer tourism supply chain with four one-directional stakeholder relations $\left(M_{1}, M_{2}, M_{3}\right.$ and $\left.M_{4}\right)$. Other supply chain models exist, for instance in some cases, a sending and receiving organisation is absent as volunteers engage directly with a host project.

*** insert Figure 2 here

Figure 2 is however too simplistic to properly understand supplier relationships. By applying collaboration theory we can understand the dynamic and interactive nature of stakeholder relations (Gray \& Wood, 1991b). A two-way exchange of knowledge, expertise and resources takes place between the stakeholders in their processes, activities and communications 
(Graci, 2013), hence we reinterpret the supply chain as bi-directional. Acknowledging exchanges as bi-directional is significant to the possibility of sustainability, in that they help to identify the potential equity of power sharing, shared decision making and value creation, as well as inter-organisational learning and joint product development amongst stakeholders. The levels of engagement and collaboration in delivering the volunteer tourism product determine the sustainability performances of equality and transparency amongst stakeholders (Austin, 2000; Gray, 1989).

In addition, linear supply chains are insufficient to measure all the collaborative relations in volunteer tourism, because the collaborative relations $\left(\mathrm{M}_{4}\right)$ between volunteers and the host community are not included. This is significant since it is the exchange of knowledge, skills and resources in this collaboration that defines the volunteer tourism product. To enclose all collaborative relations $\left(\mathrm{M}_{1}-\mathrm{M}_{4}\right)$ within the supply chain, the evaluative framework needs to adopt a more dynamic design and move away from a conventional linear model. Figure 3 illustrates a circular design, incorporating the collaborative relations by connecting both ends of the supply chain. A circular design is a more holistic representation of the volunteer tourism supply chain and is appropriate for measuring sustainability since it includes the crucial exchange and interaction between volunteers and the host community (Coghlan \& Noakes, 2012; McGehee \& Andereck, 2009). The proposed design achieves an all-inclusive framework, which incorporates all possible collaborations equally amongst stakeholders, reflecting the fact that the nature of each collaboration between the stakeholders is different. Hence, Figure 
3 incorporates $M_{5}$ and $M_{6}$, which represent additional links between stakeholders outside the sequential flow of the supply chain. These are important since direct collaborations also exist between the volunteers and the receiving organisation $\left(\mathrm{M}_{5}\right)$. The sending organisation also directly collaborates with host community members, as well as with the receiving organisation $\left(\mathrm{M}_{6}\right)$. The framework evaluates each mechanism and associated $\mathrm{CMO}$ configuration in order to determine the outcomes of the volunteer tourism's intervention by determining each individual CMO pathway.

*** insert Figure 3 here 
We begin by building the causal pathways between CMO configurations. Each stakeholder's contextual circumstance in engaging in the supply chain influences how and why the stakeholders interact with each other, and how and why this subsequently results in specific outcomes (Hunt \& Sridharan, 2010; Dalkin et al., 2015; Schmitt \& Beach, 2015; Astbury, 2013; Manzano-Santaella, 2011; de Souza, 2013). The linkages between Contexts and Mechanisms are specific causal pathways that influence each stage of the supply chain and its final outcome (Blamey \& Mackenzie, 2007). Constructing each pathway is a crucial phase in developing the evaluative framework since it needs to be designed specifically for the particular social intervention. When constructing the six two-directional pathways, however, it can be challenging to distinguish different determinants within the CMO configuration and relate them to the specific intervention (Timmins \& Miller, 2007). Existing knowledge, and the evaluator's familiarity with the interventions are therefore critical to developing and applying the evaluative framework (Hunt \& Sridharan, 2010).

The pathways of the framework are further developed based on the supply chain. These pathways determine, firstly, how stakeholders influence their collaborative relations, and, secondly, how the collaborations influence outcomes (Greenhalgh et al., 2015; Pawson \& Manzano-Santaella, 2012; Wong et al., 2016). The resulting pathways between Cs, Ms and Os provide a robust structure since there are six possibilities in configuring volunteer tourism's bi-directional causal pathways, incorporating multiple Contexts, Mechanisms and Outcomes. The six bi-directional mechanisms are based on collaborative processes and their associated 
relations between any of the four main stakeholders (Jackson \& Kolla, 2012). The pathways provide a consistent arrangement that allows for deeper exploration in evaluating complex social interventions. Since there are multiple stakeholders who each influence the volunteer tourism product in different ways, however, there are many possible $\mathrm{CMO}$ configurations and each pathway is unique. To address the complexity and diversity of volunteer tourism as a social intervention, therefore, the CMO configuration and its pathways need to be further developed and adapted. More intricacy, therefore, needs to be added to the pathways to enable the relationships to be explored at a deeper level.

Thus, to develop the evaluative framework for the specific social intervention of the volunteer tourism supply chain, and to enable an associated in-depth evaluation, a more in-depth distinction of each component within the $\mathrm{CMO}$ configuration needs to take place. Each $\mathrm{CMO}$ configuration is accordingly further developed into distinct components that encompass additional considerations and intricate attributes, described in detail in the following section. Specifically, the contextual settings of stakeholders can be divided into internal and external contextual conditions. External conditions describe the economic, social, environmental and political settings $(C)$, while internal conditions relate to each stakeholder's values, motivations and expectations (c). The mechanisms of collaborative relations are likewise divided between processes and relations (M), and describing the relations $(\mathrm{m})$. Furthermore, the outcomes are divided into the short-term and immediate outcomes (T1) of the collaborative relations (o), and the long-term $\left(\mathrm{T}_{2}\right)$ outcomes $(\mathrm{O})$, which are an accumulation of the short-term outcomes. 
Adopting this intricate approach to the six pathways is a specific contribution made in this article, which enables the evaluative framework to measure the volunteer tourism supply chain more accurately and in greater depth (Figure 4 and Figure 5). The next section explains how each of the components is populated and measured, by determining and measuring the three components of a $\mathrm{CMO}$, in turn

*** insert Figure 4 here

First, we define the contextual variables. We argue that the contextual setting of each stakeholder is predominately based on an understanding of how the supply chain analysis can measure sustainability performance. We recall that contextual settings are distinguishable by internal (c) and external (C) settings. The internal contextual conditions (c) (Astbury, 2013; De Souza, 2013; Hunt \& Sridharan, 2010; Manzano-Santaella, 2011) consist of the stakeholders' motivations, societal values and commitments, expectations, willingness and ability to engage with others within the supply chain (Austin, 2000; Beske \& Seuring, 2014; Gajda, 2004). Since each stakeholder group plays a different role in influencing the supply chain, their internal contextual conditions are different from one another; these are individually labelled as $c_{1}$ to $c_{4}$. The stakeholders' values and sustainability orientations $\left(c_{1}-c_{4}\right)$ influence their interactions with one another, leading to the supply chain's sustainability. Additionally, measuring sustainability performance requires an understanding of individuals' or organisational sustainability orientations, strategic values, a willingness to engage, commitment, and dedication to sustainable practices (c) (Austin, 2000; Beske \& Seuring, 2014; Gajda, 2004). 
Furthermore, the broader external contextual (C) settings, such as economic, political, social or environmental considerations, also influence how the stakeholders interact. Although the stakeholders engage on a micro level, external influences play a role and may originate at regional, national or international levels. It is important to include external considerations as part of the contextual settings, although care must be taken not to overload or overcomplicate the evaluative framework (Pawson \& Manzano-Santaella, 2012). Although stakeholder groups may consist of individuals or organisations, the descriptions of the contextual conditions are generally consistent. A summary of the descriptions (Figure 6) illustrates the internal and external contextual settings of each stakeholder group. These drivers and enablers trigger the measurable causal mechanisms that are explained in the next section. 
Second, we focus on the mechanisms in the CMO configuration, described as the connection between the input and output of the 'black box'. The mechanism explains the causal linkages, or certain behaviours by stakeholders, that lead to the particular outcomes of a social intervention (Astbury \& Leeuw, 2010; Dalkin et al., 2015; De Souza, 2013; Hunt \& Sridharan, 2010; Schmitt \& Beach, 2015). Observable processes and non-observable relations differentiate the mechanisms. The processes and interrelationships between Context and Outcome are described as the 'observed relationship' (Dalkin et al., 2015, p.2), which suggests that mechanisms are determined and measurable (Dalkin et al., 2015; Schmitt \& Beach, 2015). Dalkin et al. (2015) highlight that the mechanisms behave not as a simple binary on/off switch, emphasising instead their gradations and complexity. Mechanisms are a gradual continuum of actions or relationships that respond to certain contextual conditions to generate certain outcomes. Hunt \& Sridharan (2010) describe how policies do not have causal power independent of human reasoning and similarly, processes do not have the power to change unless it is within certain contextual conditions. 
We recall that we divided the causal mechanism of the evaluative framework into processes, procedures and relations $(\mathrm{M})$ which are subsequently defined by collaborative indicators $(\mathrm{m})$. Our particular conceptual framework consists of six supply chain linkages labelled as $\mathrm{M}_{1}-\mathrm{M}_{6}$ (Figure 6). The initial collaborative process between the volunteer and sending organisation consists of volunteer recruitment $\left(\mathrm{M}_{1}\right)$. An exchange of information takes place to match both volunteers and host projects by identifying the suitability of skills, location, skills needs, etc. A partnership $\left(\mathrm{M}_{2}\right)$ exists between the sending and receiving organisations that involves procedures to operate the volunteer placements, as well as strategic planning and decision making. In addition, the receiving organisation liaises with the host project $\left(M_{3}\right)$. The volunteer placement $\left(\mathrm{M}_{4}\right)$ consists of the exchange of knowledge, experience and expertise between the volunteer and the staff of the host project. During the volunteer placement, the receiving organisation liaises with the volunteer directly $\left(M_{5}\right)$ in dealing with logistics such as transportation. Finally, direct engagement $\left(\mathrm{M}_{6}\right)$ occurs between the sending organisation and the local host project if and when staff members visit the host project. In differentiating each causal mechanism, within the framework, the procedures between the stakeholders are individually evaluated based on collaboration theory.

In addition to these processes and procedures, De Souza (2013) describes how mechanisms can operate at different strata or directions. Amalgamated within the collaborative relationships between the stakeholders $(\mathrm{M})$, the evaluative framework considers both the personal collaborative relationships and the overall processes and procedures. Long-term 
decision-making practices, structures and processes, including self-assessment, reflectiveness

and continued learning, both develop, maintain and improve the volunteer tourism product and thus understanding them through the evaluative framework can make significant contributions to the evaluation of the supply chain's performance. The trust and support of other stakeholders, as well as building long-term relationships, are also crucial elements that build on mutual sharing of risks and benefits, joint product development and planning and building capacity for other stakeholders (Beske \& Seuring, 2014). A further attribute is sharing the risks and benefits of each of the stakeholders since this contributes to the continuation and performance of the whole supply chain. In the case of a weakened collaborative relationship, the whole supply chain may be affected, possibly jeopardising the final product or service (Jamal \& Getz, 1995). Thus, the supply chain's overall performance is determined based on the mechanisms between stakeholders. For example, if the relations between either the sending and receiving organisations, or the receiving organisations and the host projects are weakened due to misaligned motivations or values, then trust, respect and transparency can be compromised leading to poor outcomes of the volunteer placement. The collaborative descriptors $(\mathrm{m})$ of the interpersonal relations are incorporated into the mechanisms of the evaluative framework's CMO configuration ( Figure 6). Based on the collaboration theory literature, the descriptors $(\mathrm{m})$ of the relations between stakeholders are measured.

The effectiveness of collaboration, including community engagement and communications, are measurable qualities that define the nature of the stakeholders' relations (Austin, 2000; 
Bramwell \& Sharman, 1999; Brown, 1991; Gajda, 2004; Munanura \& Backman, 2012).

Measuring collaborative relations is a multifaceted task based on various attributes, such as the processes of integration, the level of interdependency, and the strengths of decision and policy making. Additionally, the co-existence, degree and scope of consensus amongst each stakeholder, shared aims and visions, as well as responses to external factors and influences, are all important (Bramwell \& Sharman, 1999; Gray, 1989; Roberts \& Bradley, 1991; Selsky, 1991). Furthermore, the level of exchanges in knowledge, expertise and resources, and the formation of personal relationships and cultural exchanges are significant during the volunteer placement. These exchanges constitute the volunteer tourism product, particularly between volunteers and host beneficiaries (Wearing \& Grabowski, 2011; Wearing \& McGehee, 2013). This applies to both individuals, organisations and their staff within the supply chain (Waddock, 1989; Waddock \& Post, 1995). In drawing together these attributes (Table 5), the evaluative framework measures the collaborative indicators $(\mathrm{m})$ of each of the processes and interrelations between stakeholders. The collaborative indicators systematically define and explain the complex and highly varied processes, procedures and relations. The indicators detail the pathways through which contextual conditions trigger certain mechanisms in producing particular outcomes.

Third, we determine and attempt to measure outcomes. While the importance of measuring the sustainability performances of social values and impacts on host communities is acknowledged (Coghlan \& Noakes, 2012; Lupoli \& Morse, 2014), there is little empirical 
evidence to suggest how transformative change is sustainable at community level (Forrest \&

Wiek, 2014, 2015). It is recognised that being inclusive of stakeholder collaborative relations

contributes towards sustainable communities, hence the emphasis is on measuring the outcomes of those collaborative relations, including impacts at a local level (Brown, 1991; Gajda, 2004; Munanura \& Backman, 2012). The evaluative approach also needs to allow for the inclusion of unknown and unintentional outcomes (Nanninga \& Glebbeek, 2011). Lupoli's exploratory volunteer tourism study includes the local community as a stakeholder and reveals their preferences in respect to indicators, but that study requires further development to assess local impacts (Lupoli, Morse, Bailey, \& Schelhas, 2014). Considering volunteer tourism organisations, and evaluating their performances, and its management practices, Taplin highlights the need to take account of the context when developing a methodological approach, including an understanding of the implications of different contexts (Taplin et al., 2014). Similarly with collaborative relationships, the outcomes are measurable based on the aims and objectives of the volunteer project (Gajda, 2004).

*** insert Table 6 here

The outcomes (o \& O) are differentiated between short-term outcomes (o) and long-term outcomes (0). Short-term outcomes (o) occur immediately at the point of each volunteer placement $\left(T_{1}\right)$, while long-term outcomes $(0)$ are the accumulation of many volunteer placements over a long period of time $\left(T_{2}\right)$, demonstrating transformational changes to all 
stakeholders, and ultimately the sustainability of the volunteer tourism project. Specific to the supply chain, the sustainability performance is measured by practices, for instance, that indicate transparency, accountability, and the effectiveness and nature of the collaboration (o). Thus, according to the current literature, power balance, equality and independence amongst stakeholders are critical in achieving sustainable volunteering. Accumulative shortterm outcomes may result in long-term transformational impacts (Figure 6). Thus, positive transformational change demonstrates sustainability performance, such as social mobility for example (O). Transformative change and benefits to the host project and its staff define one of the desirable outcomes in volunteer tourism (Coghlan \& Gooch, 2011; Kontogeorgopoulos, 2014). This transformative change relates to the contextual settings and causal mechanisms. The evaluative framework aims to explore if and how the volunteer tourism supply chain operates to foster transformative change and to evaluate its effectiveness in achieving sustainability performance.

\section{Conclusions}

In this article we introduce the benefits of RE as a methodology to systematically lead to causal explanations for the sustainability of stakeholder relations in the volunteer tourism supply chain. Impacts and outcomes (O), are caused by certain contextual conditions (C) triggering mechanisms such as procedures, processes and personal relations (M). An evaluative framework is designed to demonstrate the potential to test the sustainability of the supply chain of the volunteer tourism industry. This highly detailed evaluative framework 
shall help sustainable supply chain management researchers to better develop their own CMOs, based on literature, before this is further tested in the field. In this particular case, we have exemplified how the sustainability of volunteer tourism depends on the contextual circumstances of the supply chain, which in turn consists of volunteer tourism stakeholders' external environmental and internal settings and the subsequent nature of the collaborative interactions between them (M).

We have constructed the conceptual evaluative framework illustrating how the volunteer tourism stakeholders holistically relate to one another in the $\mathrm{CMO}$ configuration and its associated components $(c, m, o)$. We have provided an overview of how the configurations link together: firstly, the stakeholders' internal and external contextual conditions (c, C), secondly the interactions of observable collaborative processes $(\mathrm{M})$ and collaborative descriptors $(\mathrm{m})$ and thirdly, the short $\left(T_{1}\right)$ and long $\left(T_{2}\right)$ term outcomes $(0,0)$. The circular structure of the stakeholder groups and the differentiations between $\mathrm{CMO}$ and $\mathrm{cmo}$ are each important features of the proposed conceptual framework. Based on the relevant literature, we explained how the individual components of the $\mathrm{CMO}$ and cmo configurations are defined and measured. Next, we moved on to develop the CMO configuration. We have illustrated how each of the stakeholder groups in the supply chain relates to one another, to allow us to identify in detail each component of the conceptual framework's CMO configurations. We have defined measurable attributes and determinants of each Context Mechanism and Outcome and $(c, m, o)$ and how they contribute to the evaluative framework. To do this, we 
have outlined the different causal pathways and continue to explain the contextual circumstances (c \& C), the collaborative processes and collaborative descriptors ( $m \&$ \&), and, lastly, the short and long-term outcomes (o \& O) over time $\left(T_{1} \& T_{2}\right)$. These are summarised in Figure 6.

*** insert Figure 6 here 
We have contributed to the development of RE as a methodology, by showing a systematic process to define Contexts Mechanisms and Outcomes that will subsequently help researchers to map out and test potential CMO configurations. In bridging theory to practice, building these $\mathrm{CMO}$ configurations is an essential step to explain the interrelations which operationalise the mechanism (Manzano, 2016; Marchal et al., 2016; Pawson \& ManzanoSantaella, 2012), which will determine the potential methods of measurement of why volunteer tourism stakeholders' contextual conditions and how their relations influence particular outcomes of sustainability performance. Theories to explain such interrelationships are derived from academic or grey literature (Manzano, 2016; Marchal et al., 2016), and our study shows is a first step to show how researchers can map out the components of CMOs using collaboration theory and supply chain analysis. Our aim is that our application of RE and collaboration theory shows potentially fruitful methods for systematic analysis of supply chain stakeholder relations, and in doing so we can evaluate and improve the sustainability performance of the volunteer tourism sector. 


\section{References}

Ahi, P., \& Searcy, C. (2015). Measuring social issues in sustainable supply chains. Measuring Business Excellence, 19(1), 33-45. https://doi.org/10.1108/MBE-11-2014-0041

Astbury, B. (2013). Some reflections on Pawson's Science of Evaluation: A Realist Manifesto. Evaluation, 19(4), 383-401. https://doi.org/10.1177/1356389013505039

Astbury, B., \& Leeuw, F. L. (2010). Unpacking Black Boxes: Mechanisms and Theory Building in Evaluation. American Journal of Evaluation, 31(3), 363-381. https://doi.org/10.1177/1098214010371972

Austin, J. E. (2000). Strategic Collaboration Between Nonprofits and Businesses. Nonprofit and Voluntary Sector Quarterly, 29(1), 69-97. https://doi.org/10.1177/089976400773746346

Bai, C., \& Sarkis, J. (2014). Determining and applying sustainable supplier key performance indicators. Supply Chain Management: An International Journal, 19(3), 275-291. https://doi.org/10.1108/SCM-12-2013-0441

Beske, P., \& Seuring, S. (2014). Putting sustainability into supply chain management. Supply Chain Management: An International Journal, 19(3), 322-331. https://doi.org/10.1108/SCM-12-2013-0432

Blamey, A., \& Mackenzie, M. (2007). Theories of change and realistic evaluation: peas in a pod or apples and oranges? Evaluation, 13(4), 439-455. https://doi.org/10.1177/1356389007082129

Bramwell, B., \& Sharman, A. (1999). Collaboration in Local Tourism Policymaking. Annals of Tourism Research, 26(2), 392-415. https://doi.org/10.1016/S0160-7383(98)00105-4

Bramwell, B., \& Sharman, A. (2000). Approaches to sustainable tourism planning and community participation The case of the Hope Valley. In G. Richards \& D. Hall (Eds.), Tourism and Sustainable Community Development (1st ed., pp. 309-310). Abington, Oxon: Routledge. https://doi.org/10.1016/0261-5177(96)87005-1

Braziotis, C., Bourlakis, M., Rogers, H., \& Tannock, J. (2013). Supply chains and supply networks: distinctions and overlaps. Supply Chain Management: An International Journal, 18(6), 644-652. https://doi.org/10.1108/SCM-07-2012-0260

Brown, L. D. (1991). Bridging Organizations and Sustainable Development. Human Relations, 44(8), 807-831. https://doi.org/10.1177/001872679104400804

Brown, L. D., \& Korten, D. C. (1989). Understanding Voluntary Organizations Guidelines for Donors.

Burrai, E., Font, X., \& Cochrane, J. (2015). Destination Stakeholders' Perceptions of Volunteer Tourism: An Equality Theory Approach. International Journal of Tourism Research, 17(5), 451-459. https://doi.org/https://doi.org/10.1002/jtr.2012

Bussell, H., \& Forbes, D. (2002). Understanding the volunteer market: the what, where, who and why of volunteering. International Journal of Nonprofit and Voluntary Sector Marketing, 7(3), 244-257. https://doi.org/10.1002/nvsm.183

Byng, R., Norman, I., \& Redfern, S. (2005). Using Realistic Evaluation to Evaluate a Practice- 
level Intervention to Improve Primary Healthcare for Patients with Long-term Mental Illness. Evaluation, 11(1), 69-93. https://doi.org/10.1177/1356389005053198

Coghlan, A., \& Gooch, M. (2011). Applying a transformative learning framework to volunteer tourism. Journal of Sustainable Tourism, 19(6), 713-728.

https://doi.org/10.1080/09669582.2010.542246

Coghlan, A., \& Noakes, S. (2012). Towards an Understanding of the Drivers of Commercialization in the Volunteer Tourism Sector. Tourism Recreation Research, 37(2), 123-131. https://doi.org/10.1080/02508281.2012.11081697

Coryn, C. L. S., Noakes, L. a., Westine, C. D., \& Schroter, D. C. (2010). A Systematic Review of Theory-Driven Evaluation Practice From 1990 to 2009. American Journal of Evaluation, 32(2), 199-226. https://doi.org/10.1177/1098214010389321

Dalkin, S. M., Greenhalgh, J., Jones, D., Cunningham, B., \& Lhussier, M. (2015). What's in a mechanism? Development of a key concept in realist evaluation. Implementation Science, 10(1), 49. https://doi.org/10.1186/s13012-015-0237-x

De Souza, D. E. (2013). Elaborating the Context-Mechanism-Outcome configuration (CMOc) in realist evaluation: A critical realist perspective. Evaluation, 19(2), 141-154. https://doi.org/10.1177/1356389013485194

Dillman, L. M. (2013). Comparing evaluation activities across multiple theories of practice. Evaluation and Program Planning, 38, 53-60. https://doi.org/10.1016/j.evalprogplan.2012.03.014

Dos Santos, M. A. O., Svensson, G., \& Padin, C. (2014). Implementation, monitoring and evaluation of sustainable business practices: framework and empirical illustration. Corporate Governance: The International Journal of Business in Society, 14(4), 515-530. https://doi.org/10.1108/CG-02-2013-0022

Erol, I., Sencer, S., \& Sari, R. (2011). A new fuzzy multi-criteria framework for measuring sustainability performance of a supply chain. Ecological Economics, 70(6), 1088-1100. https://doi.org/10.1016/j.ecolecon.2011.01.001

Forrest, N., \& Wiek, A. (2014). Learning from success - Toward evidence-informed sustainability transitions in communities. Environmental Innovation and Societal Transitions, 12, 66-88. https://doi.org/10.1016/j.eist.2014.01.003

Forrest, N., \& Wiek, A. (2015). Success factors and strategies for sustainability transitions of small-scale communities - Evidence from a cross-case analysis. Environmental Innovation and Societal Transitions, 17, 22-40. https://doi.org/10.1016/j.eist.2015.05.005

Fu, X., Zhu, Q., \& Sarkis, J. (2012). Evaluating green supplier development programs at a telecommunications systems provider. International Journal of Production Economics, 140(1), 357-367. https://doi.org/10.1016/j.ijpe.2011.08.030

Gajda, R. (2004). Utilizing collaboration theory to evaluate strategic alliances. American Journal of Evaluation, 25(1), 65-77. https://doi.org/10.1177/109821400402500105

Gold, S., Seuring, S., \& Beske, P. (2010). Sustainable Supply Chain Management and InterOrganizational Resources: A Literature Review. Corporate Governance: The International Journal of Business in Society, 17, 230-245.

https://doi.org/10.1002/csr.207 
Graci, S. (2013). Collaboration and Partnership Development for Sustainable Tourism. Tourism Geographies, 15(1), 25-42. https://doi.org/10.1080/14616688.2012.675513

Gray, B. (1989). Collaborating: Finding Common Ground For Multiparty Problems (First). San Francisco, California: Jossey-Bass Inc., Publishers.

Gray, B., \& Wood, D. J. (1991). Toward a Comprehensive Theory of Collaboration. The Journal of Applied Behavioral Science, 27(2), 139-162. https://doi.org/10.1177/0021886391272001

Greenhalgh, T., Wong, G., Jagosh, J., Greenhalgh, J., Manzano, A., Westhorp, G., \& Pawson, R. (2015). Protocol-the RAMESES II study: developing guidance and reporting standards for realist evaluation. BMJ Open, 5(8), 1-9. https://doi.org/10.1136/bmjopen-2015008567

Hall, I., \& Hall, D. (2004). Evaluation and Social Research (First). Basingstoke, UK: Palgrave Macmillan.

Harms, D., Hansen, E. G., \& Schaltegger, S. (2013). Strategies in sustainable supply chain management: An empirical investigation of large german companies. Corporate Social Responsibility and Environmental Management, 20(4), 205-218. https://doi.org/10.1002/csr.1293

Hunt, K. S., \& Sridharan, S. (2010). A Realist Evaluation Approach to Unpacking the Impacts of the Sentencing Guidelines. American Journal of Evaluation, 31(4), 463-485. https://doi.org/10.1177/1098214010371817

Jackson, S. F., \& Kolla, G. (2012). A New Realistic Evaluation Analysis Method: Linked Coding of Context, Mechanism, and Outcome Relationships. American Journal of Evaluation, 33(3), 339-349. https://doi.org/10.1177/1098214012440030

Jaeni, J., \& Timonen, O. (2014). Encounters in Volunteer Tourism -A case Study from Zambia. In H. B. Clausen, V. Anderson, \& S. Gyimothy (Eds.), Global Mobilities and Tourism Development, a Community Perspective (1.). Aalborg: Aalborg University Press.

Jamal, T., \& Getz, D. (1995). Collaboration Theory and Community Tourism Planning. Annals of Leisure Research, 22(1), 186-204. https://doi.org/http://doi.org/0160- 7383 (94)00067-0

Kache, F., \& Seuring, S. (2014). Linking collaboration and integration to risk and performance in supply chains via a review. Supply Chain Management: An International Journal, 19(5/6), 664-682. https://doi.org/10.1108/SCM-12-2013-0478

Kontogeorgopoulos, N. (2014). The relationship between volunteer tourism and development in Thailand. Tourism, 62(3), 239-255.

Lupoli, C. A., \& Morse, W. C. (2014). Assessing the Local Impacts of Volunteer Tourism: Comparing Two Unique Approaches to Indicator Development. Social Indicators Research. https://doi.org/10.1007/s11205-014-0606-x

Lupoli, C. A., Morse, W. C., Bailey, C., \& Schelhas, J. (2014). Assessing the impacts of international volunteer tourism in host communities: a new approach to organizing and prioritizing indicators. Journal of Sustainable Tourism, 22(6), 898-921. https://doi.org/10.1080/09669582.2013.879310

Lupoli, C. A., Morse, W. C., Bailey, C., \& Schelhas, J. (2015). Indicator development 
methodology for volunteer tourism in host communities: creating a low-cost, locally applicable, rapid assessment tool. Journal of Sustainable Tourism, 23(5), 726-747. https://doi.org/10.1080/09669582.2015.1008498

Manzano-Santaella, A. (2011). A realistic evaluation of fines for hospital discharges: Incorporating the history of programme evaluations in the analysis. Evaluation, 17(1), 21-36. https://doi.org/10.1177/1356389010389913

Manzano, A. (2016). The craft of interviewing in realist evaluation. Evaluation, 22(3), 1-19. https://doi.org/10.1177/1356389016638615

Marchal, B., van Belle BTC, S., Josefien van Olmen, B., Hoerée, T., \& Kegels, G. (2016). Is realist evaluation keeping its promise? A review of published empirical studies in the field of health systems research review of realist evaluations in health systems research. Evaluation, 18(2), 192-212. https://doi.org/10.1177/1356389012442444

McGehee, N. G. (2014). Volunteer tourism: evolution, issues and futures. Journal of Sustainable Tourism, 22(6), 847-854. https://doi.org/10.1080/09669582.2014.907299

McGehee, N. G., \& Andereck, K. (2009). Volunteer tourism and the "voluntoured": the case of Tijuana, Mexico. Journal of Sustainable Tourism, 17(1), 39-51. https://doi.org/10.1080/09669580802159693

Munanura, I. E., \& Backman, K. F. (2012). Stakeholder Collaboration as a Tool for Tourism Planning - A Developing Country's Perspective. Journal of Tourism, 13(1), 23-39. Retrieved from http://www.jothnbgu.in/article/JOT June 2012.pdf

Nanninga, M., \& Glebbeek, A. (2011). Employing the teacher-learner cycle in realistic evaluation: A case study of the social benefits of young people's playing fields. Evaluation, 17(1), 73-87. https://doi.org/10.1177/1356389010393586

Pawson, R. (2013). The Science of Evaluation, A Realist Manifesto (First). London: Sage Publications Ltd.

Pawson, R., \& Manzano-Santaella, A. (2012). A realist diagnostic workshop. Evaluation, 18(2), 176-191. https://doi.org/10.1177/1356389012440912

Pawson, R., \& Tilley, N. (1997). Realistic Evaluation (First). London, UK: Sage Publications Ltd.

Raymond, E. M., \& Hall, C. M. (2008). The Development of Cross-Cultural (Mis)Understanding Through Volunteer Tourism. Journal of Sustainable Tourism, 16(5), 530. https://doi.org/10.2167/jost796.0

Roberts, N. C., \& Bradley, R. T. (1991). Stakeholder Collaboration and Innovation: A Study of Public Policy Initiation at the State Level. The Journal of Applied Behavioral Science, 27(2), 209-227. https://doi.org/10.1177/0021886391272004

Satolo, E. G., \& Simon, A. T. (2015). Critical analysis of assessment methodologies for intraorganizational sustainability. Management of Environmental Quality : An International Journal, 26(2), 214-232. https://doi.org/10.1108/MEQ-09-2013-0108

Schaltegger, S., \& Burritt, R. (2014). Measuring and Managing Sustainability Performance of Supply Chains. Review and Sustainability Supply Chain Management Framework. Supply Chain Management: An International Journal, 19, 232-241. https://doi.org/10.1108/SCM-02-2014-0061 
Schmitt, J., \& Beach, D. (2015). The contribution of process tracing to theory-based evaluations of complex aid instruments. Evaluation, 21(4), 429-447. https://doi.org/10.1177/1356389015607739

Selsky, J. W. (1991). Lessons in Community Development: An Activist Approach to Stimulating Interorganizational Collaboration. The Journal of Applied Behavioral Science, 27(1), 91-115. https://doi.org/10.1177/0021886391271005

Sin, H., Oakes, T., \& Mostafanezhad, M. (2015). Traveling for a cause: Critical examinations of volunteer tourism and social justice. Tourist Studies, 15(2), 119-131. https://doi.org/10.1177/1468797614563380

Taplin, J. E., Dredge, D., \& Scherrer, P. (2014). Monitoring and evaluating volunteer tourism: a review and analytical framework. Journal of Sustainable Tourism, 22(6), 874-897. https://doi.org/10.1080/09669582.2013.871022

Tejada, M. P., \& Liñán, F. (2009). An Analysis of Tourism Global Value Chains. Analysis, 6(3 \& 4), 96-110.

Tilley, N. (2000). Realistic Evaluation : An Overview. In Founding conference of the Danish Evaluation Society (pp. 1-13). Aarhus, DK.

Timmins, P., \& Miller, C. (2007). Making evaluations realistic: the challenge of complexity. Support for Learning, 22(1), 9-16. https://doi.org/10.1111/j.1467-9604.2007.00439.x

Tomazos, K., \& Butler, R. (2009). Volunteer Tourism: The New Ecotourism? Anatolia-An International Journal of Tourism and Hospitality Research, 20(1), 196-211. https://doi.org/10.1080/13032917.2009.10518904

Varsei, M., Soosay, C., Fahimnia, B., \& Sarkis, J. (2014). Framing sustainability performance of supply chains with multidimensional indicators. Supply Chain Management: An International Journal, 19(3), 242-257. https://doi.org/10.1108/SCM-12-2013-0436

Waddock, S. A. (1989). Understanding Social Partnerships: An Evolutionary Model of Partnership Organizations. Administration \& Society, 21(1), 78-100. https://doi.org/10.1177/009539978902100105

Waddock, S. A., \& Post, J. E. (1995). Catalytic Alliances for Social Problem Solving. Human Relations, 48(8), 951-973. https://doi.org/10.1177/001872679504800807

Wand, T., White, K., \& Patching, J. (2010). Applying a realist(ic) framework to the evaluation of a new model of emergency department based mental health nursing practice. Nursing Inquiry, 17(3), 231-239. https://doi.org/10.1111/j.1440-1800.2010.00488.x

Wearing, S., \& Grabowski, S. (2011). Volunteer Tourism and intercultural exchange. In A. M. Benson (Ed.), Volunteer Tourism Theoretical Framework to Practical Application (1st ed., pp. 193-210). Abington, Oxon: Routledge.

Wearing, S., \& McGehee, N. G. (2013). Volunteer tourism: A review. Tourism Management, 38, 120-130. https://doi.org/10.1016/j.tourman.2013.03.002

Wolpe, R. (2016). Findings and Lessons from a Meta-review of Evidence on the Impacts of Interventions to Promote Entrepreneurship in Developing Country Contexts. Journal of Entrepreneurship and Innovation in Emerging Economies, 2(2), 175-198.

https://doi.org/10.1177/2393957516647263 
Wong, G., Westhorp, G., Manzano, A., Greenhalgh, J., Jagosh, J., \& Greenhalgh, T. (2016). RAMESES II reporting standards for realist evaluations. BMC Medicine, 14(1), 96. https://doi.org/10.1186/s12916-016-0643-1

Figure 1: Realistic Evaluation explaining Transformative Change

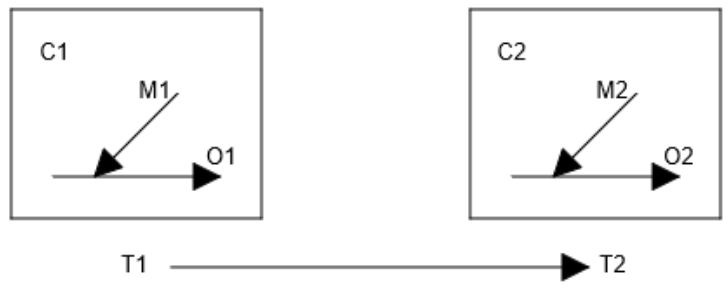

Source: Pawson \& Tilley, 1997. 
Table 1: Basic Construction of the Evaluative Framework

\begin{tabular}{|c|l|l|}
\hline $\begin{array}{c}\text { Realistic } \\
\text { Evaluation }\end{array}$ & \multicolumn{1}{|c|}{ Indicator dimensions } & \multicolumn{1}{c|}{$\begin{array}{c}\text { Categories of sustainable performance in } \\
\text { supply chain }\end{array}$} \\
\hline C & Strategic values of stakeholders & Orientation \\
\hline M & $\begin{array}{l}\text { Processes, relations and } \\
\text { structure }\end{array}$ & $\begin{array}{l}\text { Collaboration, continuity, risk management, } \\
\text { proactivity }\end{array}$ \\
\hline O & Sustainability performance & Transformative change \\
\hline
\end{tabular}

Source: authors, based on Beske \& Seuring, 2014. 
Figure 2 The Volunteer Tourism Supply Chain

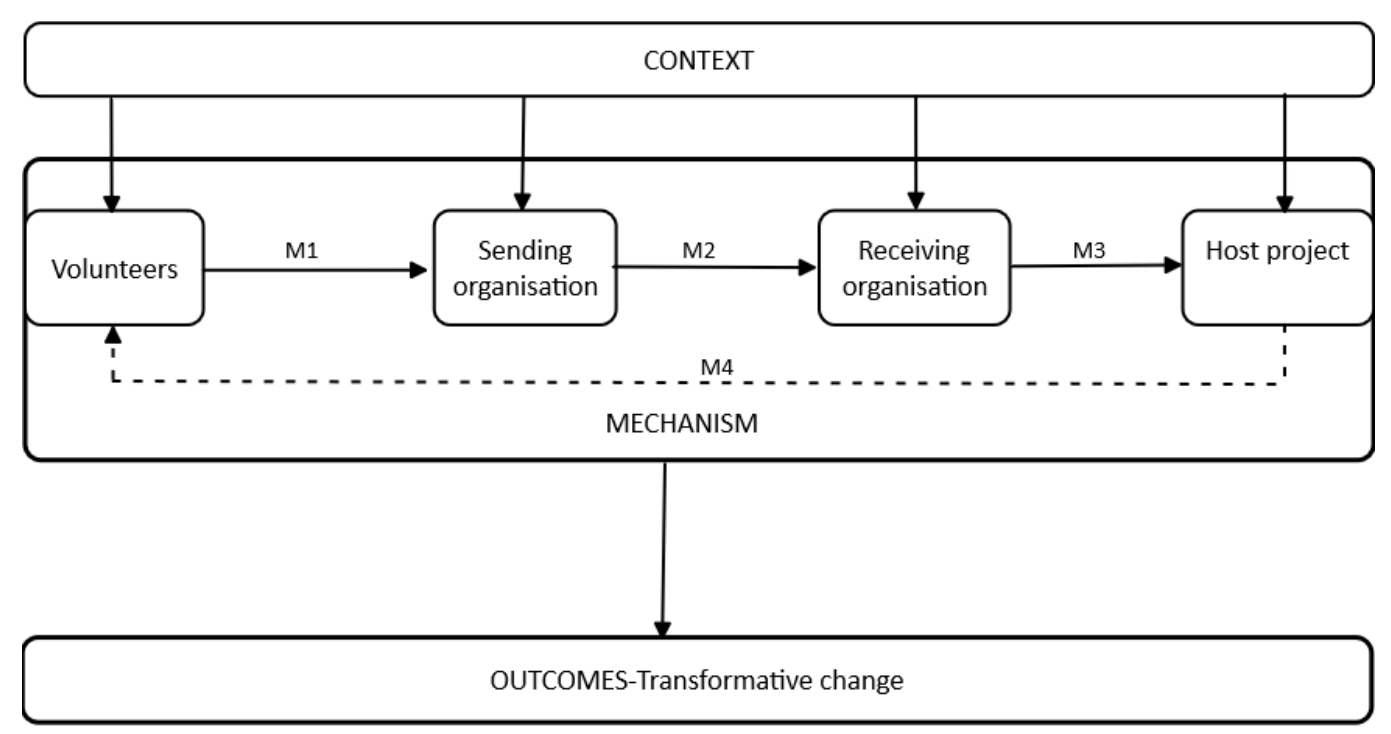

Source: authors. 
Figure 3: Circular Supply Chain Framework

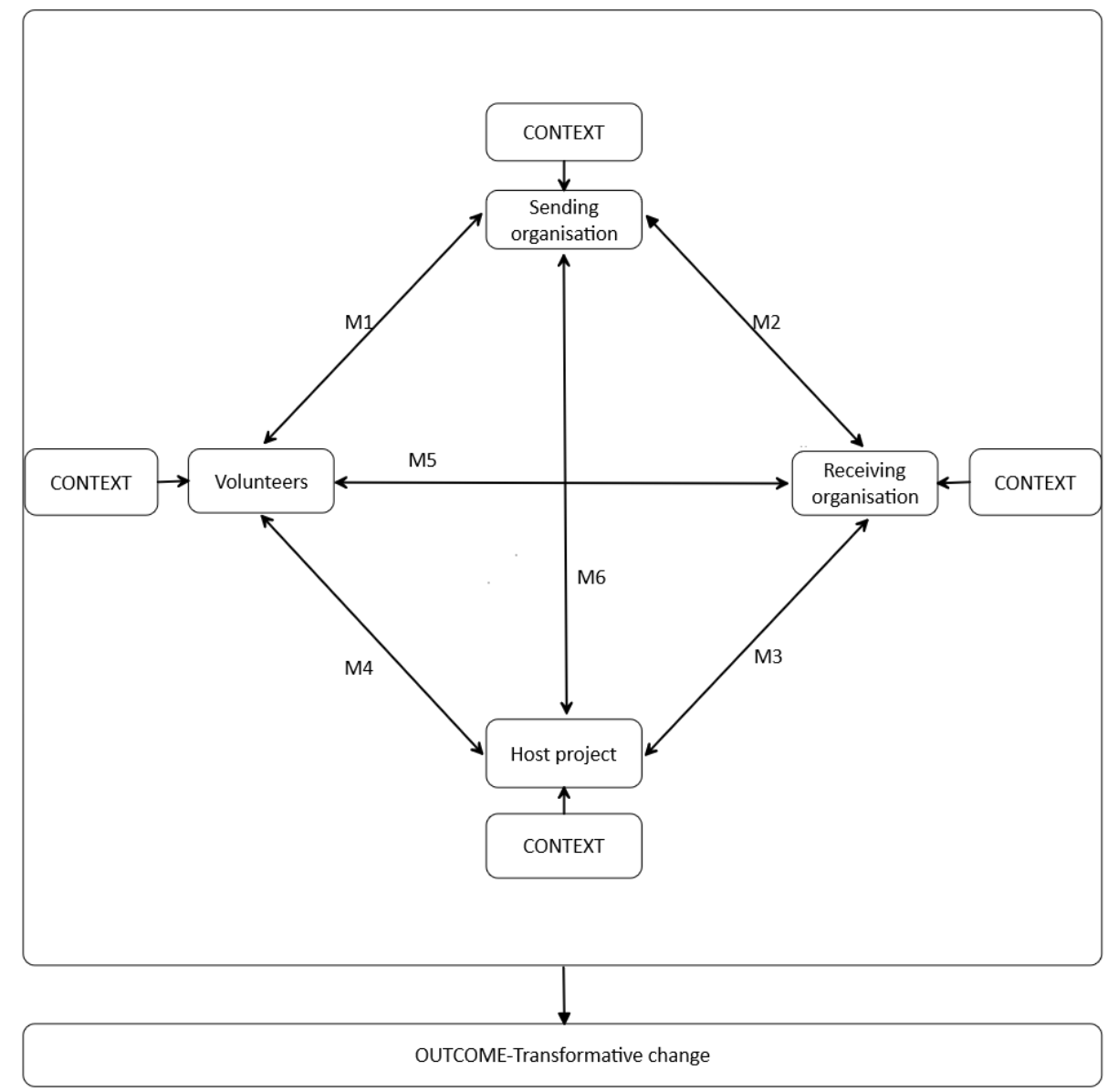

Source: authors. 

Figure 4: The Evaluative Framework

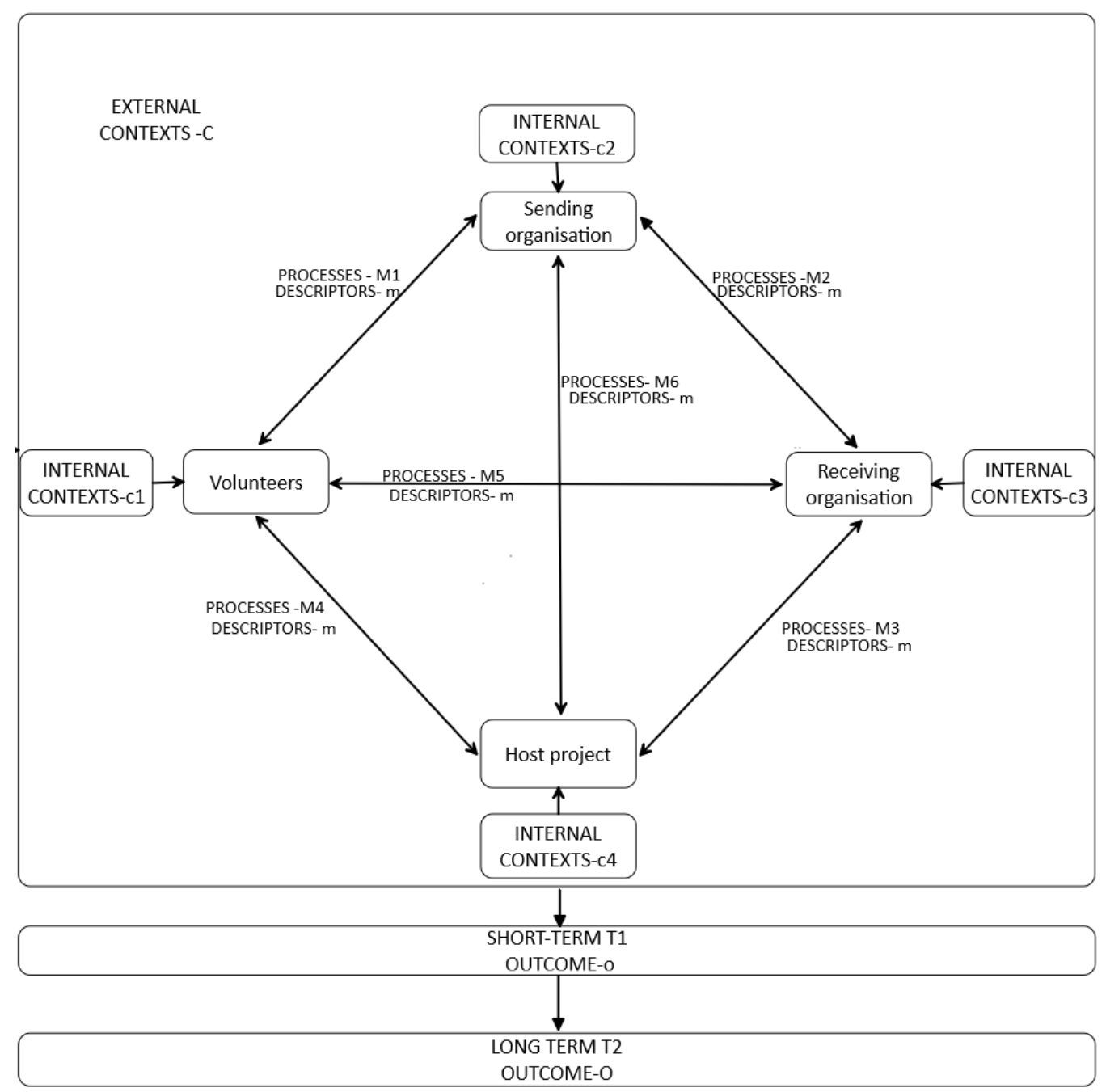

Legend

$\begin{array}{llll}\mathrm{C} & \text { External contexts } & \mathrm{c} & \text { Internal contexts } \\ \mathrm{M} & \text { Collaborative processes } & \mathrm{m} & \text { Collaborative descriptors } \\ \mathrm{O} & \text { Long term outcome } & \mathrm{o} & \text { Short term outcome } \\ \mathrm{T}_{2} & \text { Long term } & \mathrm{T}_{1} & \text { Short term }\end{array}$

Source: authors. 
Figure 5: Summary of the CMO Configuration

\begin{tabular}{|c|l|l|l|}
\hline \multicolumn{4}{|c|}{ EXTERNAL CONTEXTUAL CONDITIONS C } \\
\hline \multicolumn{4}{|c|}{ economic, social, political, environmental } \\
\hline \multicolumn{4}{|c|}{ INTERNAL CONTEXTUAL CONDITIONS c } \\
\hline Volunteer & \multicolumn{1}{|c|}{$\begin{array}{c}\text { Sending organisation } \\
\text { C1 }\end{array}$} & \multicolumn{1}{|c|}{ C2 } & \multicolumn{1}{c|}{ C3 } \\
\hline $\begin{array}{l}\text {-motivation, } \\
\text { expectations } \\
\text {-societal values and } \\
\text { commitment } \\
\text {-willingness to engage }\end{array}$ & $\begin{array}{l}\text {-organisational motivation, } \\
\text { expectations } \\
\text {-societal values and } \\
\text { commitment (vision and } \\
\text { purpose) } \\
\text {-willingness to engage }\end{array}$ & $\begin{array}{l}\text {-organisational motivation, } \\
\text { expectations } \\
\text {-societal values and } \\
\text { commitment (vision and } \\
\text { purpose) } \\
\text {-willingness to engage }\end{array}$ & $\begin{array}{l}\text {-motivation, expectations } \\
\text {-societal values and } \\
\text { commitment } \\
\text {-willingness to engage }\end{array}$ \\
\hline
\end{tabular}

\begin{tabular}{|lc|}
\hline & COLLABORATIVE PROCESSES \\
\hline$M_{1}$ Volunteer Recruitment & $M_{4}$ Volunteer Placement \\
$M_{2}$ Partnership Management & $M_{5}$ Volunteer Management \\
$M_{3}$ Host Project Management & $M_{6}$ Host Project Assessment \\
\hline
\end{tabular}

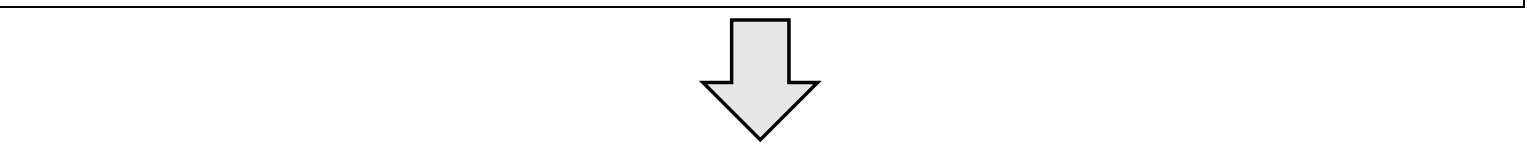

\section{COLLABORATIVE DESCRIPTORS}

-willingness to engage $\left(m_{\text {wes }}\right)$

-joint problem solving $\left(m_{\mathrm{jps}}\right)$

-level of integration and engagement $\left(m_{\text {ine }}\right)$

-level of exchange of skills and expertise $\left(m_{\text {exk }}\right)$

-sharing aims and values ( $\left.m_{\text {sav }}\right)$

-building capacity for other stakeholders ( $m_{\text {cas }}$ )

-joint planning and product development $\left(m_{j p p}\right)$

-joint decision making and power sharing $\left(m_{j d m}\right)$

-sharing risks and benefits $\left(m_{\text {srb }}\right)$

-joint reflectivity and monitoring $\left(\mathrm{m}_{\mathrm{jrm}}\right)$

-cultural exchange $\left(m_{\text {cul }}\right)$

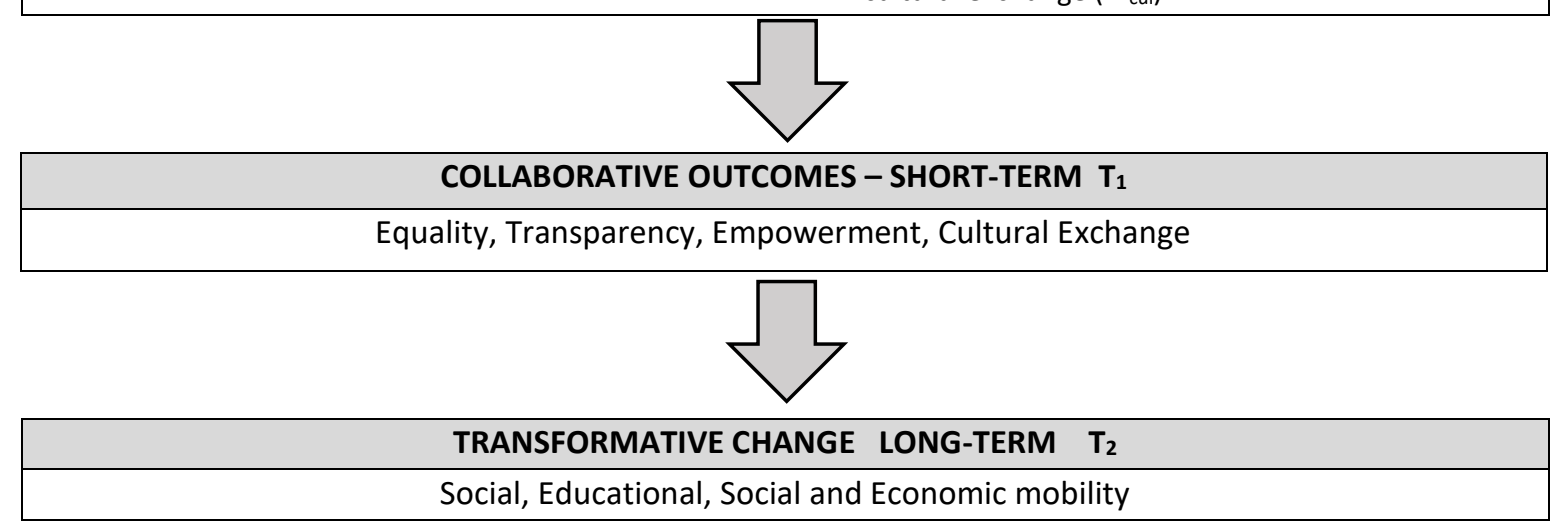

Source: authors. 